\title{
Actualización de las investigaciones arqueológicas en el Espinal Nororiental: el sitio Arroyo Cululú 1 (AC1) (Esperanza, provincia de Santa Fe)
}

\author{
Paula E. Galligani \\ (iD) https://orcid.org/0000-0002-3949-5333 \\ División Arqueología, Facultad de Ciencias Naturales y Museo, Universidad Nacional de La Plata (UNLP) - Consejo \\ Nacional de Investigaciones Científicas y Técnicas (CONICET). Paseo del Bosque s/n (CP B1900FWA), La Plata \\ Buenos Aires, Argentina. E-mail: paulagalligani@hotmail.com
}

\section{Fernando Balducci}

(iD) https://orcid.org/0000-0001-9890-059X

Instituto de Arqueología, Facultad de Filosofía y Letras, Universidad de Buenos Aires (UBA) - Consejo Nacional de Investigaciones Científicas y Técnicas (CONICET). 25 de mayo 217, $3^{\circ}$ piso (CP C1002ABE), Ciudad Autónoma de Buenos Aires, Argentina. E-mail: ferbalducci@gmail.com

\section{Julieta I. Sartori}

(iD) https://orcid.org/0000-0001-6684-5039

Laboratorio de Sedimentología-Geomorfología Fluvial, Facultad de Ingeniería y Ciencias Hídricas, Universidad Nacional del Litoral (UNL) - Consejo Nacional de Investigaciones Científicas y Técnicas (CONICET). Ruta Nacional $\mathrm{N}^{\circ} 168, \mathrm{Km}$ 472,4 (CP 3000), Santa Fe, Santa Fe, Argentina. E-mail: julisartori@gmail.com

Recibido: 13 de marzo de 2020 Aceptado: 8 de julio de 2020

\section{Resumen}

En este artículo se presenta una actualización de las investigaciones efectuadas en el sitio arqueológico Arroyo Cululú 1 (AC1), localizado en la cuenca homónima, en las cercanías de la localidad de Esperanza (departamento Las Colonias, provincia de Santa Fe). A pesar de las inundaciones periódicas que sufre el sitio, se pudo acceder en varias oportunidades, realizándose recolecciones superficiales en los años 2016 y 2017 y excavaciones sistemáticas en el 2018. A partir de las tareas de campo, se halló gran cantidad de materiales cerámicos -fundamentalmente lisos, con escasa presencia de tiestos con decoración-, elementos arqueofaunísticos - dentro de los que se destacan taxa como Lama sp. y Ozotoceros bezoarticus- y tres entierros humanos, con distintas modalidades de inhumación. El objetivo de esta comunicación es presentar los resultados de los análisis del registro recuperado durante las dos últimas intervenciones (2017 y 2018), en conjunto con los datos obtenidos de la primera prospección (2016). Se espera que la nueva información generada contribuya a lograr un conocimiento más profundo de los grupos cazadores-recolectores-pescadores que habitaron el Espinal santafesino en el pasado y a incluir esta zona en los debates que se desarrollan desde la arqueología regional. 


\title{
An update on archaeological research in the Northeastern Espinal phytogeographic province: Arroyo Cululú 1 (AC1) site (Esperanza, Santa Fe, Argentina)
}

\begin{abstract}
We present an update on the archaeological research carried out at the Arroyo Cululú 1 (AC1) archaeological site, located in the homonymous basin, near Esperanza city (Las Colonias department, Santa Fe province). Despite the periodic floods affecting the site, it was accessible on several occasions, allowing surface collection fieldworks in 2016 and 2017, and systematic excavations in 2018. A large number of pottery sherds - mostly smooth sherds and also a few decorated pots- were found in the field. Archaeofaunal remains corresponding to taxa like Lama sp. and Ozotoceros bezoarticus, and three human inhumations exhibiting different burial practices were also recovered. This paper aims to present the results of the analysis of the material remains recovered during the last two interventions (2017 and 2018) along with the data obtained from the first archaeological survey (2016). This new information will contribute to gain a deeper knowledge of the hunter-gatherer-fisher groups that inhabited the Northeastern Espinal phytogeographic province in the past, and allows including this area in the regional archaeological debates.
\end{abstract}

KEYWORDS: Central Santa Fe; North Salado river Basin; Human Burial; Pottery; Faunal Remains.

\section{Introducción}

El tramo inferior de la cuenca del río Salado del Norte (de aquí en más río Salado) cuenta con estudios tempranos en lo que respecta a trabajos arqueológicos y paleontológicos que se remontan a las primeras décadas del siglo XX (v.g. Castellanos, 1924; Frenguelli, 1920; Vignati, 1923, 1931, 1934), momentos en los cuales las condiciones hidrológicas habrían sido más favorables, lo que permitía el ingreso recurrente a las zonas cercanas a los cursos de agua (Paoli et al., 2013). Como resultado de las revisiones de estos trabajos y de investigaciones propias, Ceruti $(1988,1995)$ adjudica a los materiales hallados en el área a lo que él define como Entidad Cultural Esperanza (Ceruti, 1986), categoría que hace referencia a grupos cazadores-recolectores-pescadores pedestres que se desplazaban estacionalmente desde el río Paraná hasta las Sierras Cordobesas (Ceruti, 1986, 2000, 2006).

Luego de 20 años sin investigaciones sistemáticas en la zona, en el año 2015 comenzó a trabajarse nuevamente, desde los proyectos "Modelos de preservación ósea diferencial en la cuenca fluvial Salado-Coronda (provincia de Santa Fe): Tafonomía Regional en perspectiva arqueológica" y "Análisis arqueológico de la tecnología cerámica de cuencas fluviales del centro-este santafesino (ríos Coronda y Salado del Norte): diversidad de líneas de abordaje". Las prospecciones realizadas en el marco de estos proyectos dieron como resultado el hallazgo de nuevas evidencias de ocupación humana, específicamente en las inmediaciones de la confluencia del río Salado y del arroyo Cululú, localizándose el sitio Arroyo Cululú 1 (AC1) a finales del año 2016. En ese momento se realizaron las primeras recolecciones superficiales de materiales, recuperándose restos faunísticos y cerámicos, cuyos análisis fueron publicados en un trabajo previo (Galligani, Balducci, Sartori y Barrientos, 2017).

Las diversas intervenciones al sitio estuvieron mediadas por uno de los problemas más graves que presenta la zona de estudio: las inundaciones periódicas. Las mismas ocurren con frecuencias y permanencias variables del agua -aunque generalmente 
prolongadas en el tiempo-, que dificultan el acceso al terreno. No obstante, si bien durante la casi totalidad del año 2017 el sitio se mantuvo completamente inundado, se pudo acceder al mismo hacia el mes de diciembre y en dos oportunidades durante el año 2018. Producto de estas últimas tareas de campo, se hallaron nuevos materiales arqueológicos, que incluyen fragmentos cerámicos, restos arqueofaunísticos y entierros humanos, cuyos análisis y resultados se presentan en este trabajo, en conjunto con aquellos correspondientes a la intervención del año 2016, ya publicados en Galligani et al. (2017). Además, esta información se contextualiza con aquella disponible para la cuenca del río Salado y áreas aledañas (v.g. Paraná medio, Sierras de Córdoba).

\section{Sitio arqueológico Arroyo Cululú 1}

En diciembre de 2016, a partir de indicaciones proporcionadas por el Sr. Hugo Galimberti, se halló el sitio Arroyo Cululú 1 (AC1), en un campo actualmente utilizado para la cría de ganado vacuno, adyacente a la margen derecha del arroyo homónimo en la localidad de Esperanza (departamento Las Colonias, provincia de Santa Fe). El sitio se ubica a unos $1.500 \mathrm{~m}$ aguas arriba de la desembocadura del mencionado arroyo en el río Salado y se destaca la presencia de un monte de especies leñosas en las cercanías del mismo (Figura 1A).

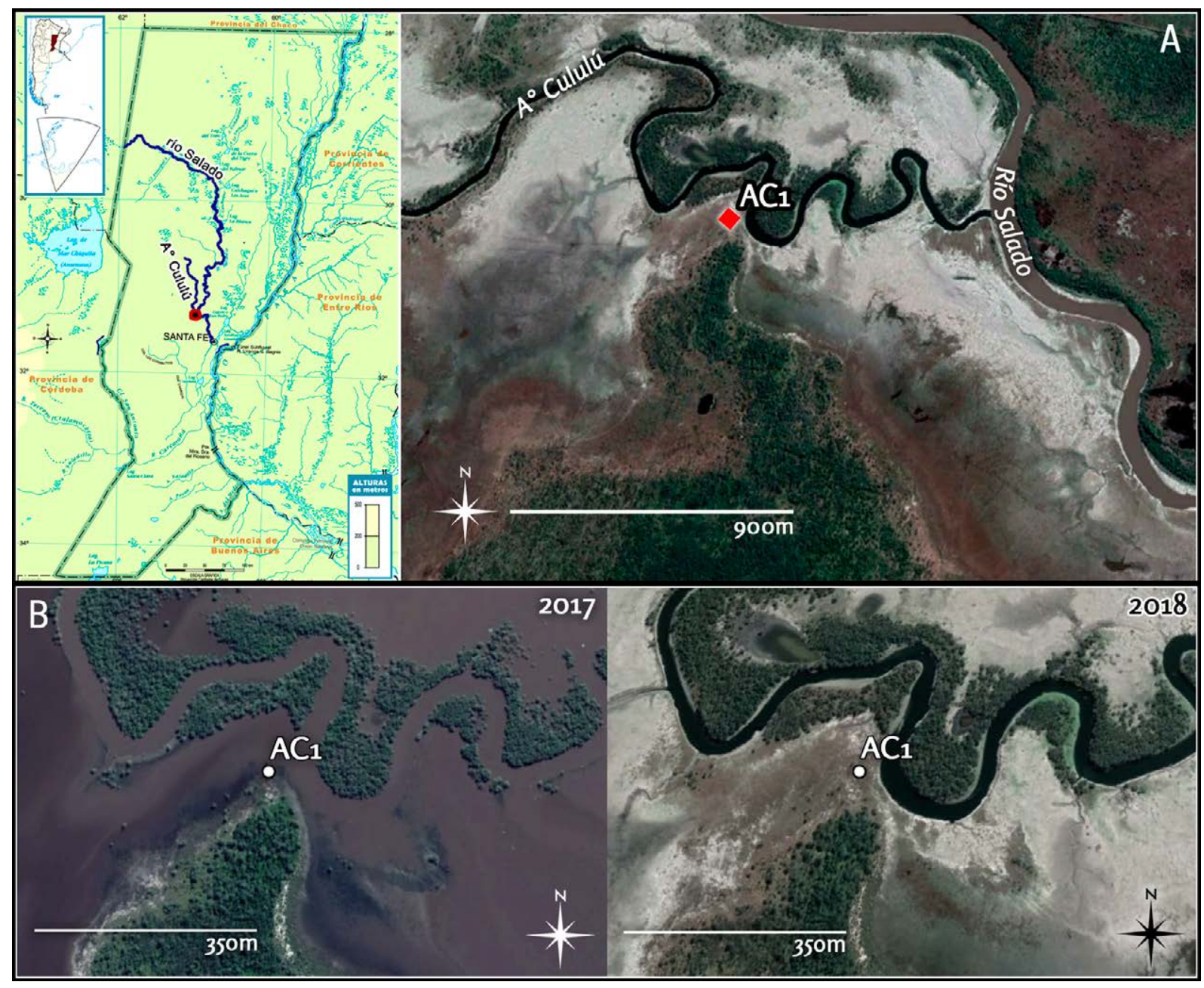

Figura 1. A) Localización del sitio Arroyo Cululú 1 (AC1); B) imágenes satelitales de la zona donde se emplaza el sitio en período de inundación (izquierda) y de sequía (derecha). Imágenes tomadas de Google Earth 7.3.2.5776 (mayo de 2019). 
Biogeográficamente, se inserta en el sector nororiental de la ecorregión del Espinal, la cual es definida, en la provincia de Santa Fe, como una zona de transición entre las llanuras pampeanas y las planicies chaqueñas (Burkart, Bárbaro, Sánchez y Gómez, 1999; Oakley, Prado y Ádamoli, 2005). El paisaje de esta ecorregión se caracteriza por ambientes de llanuras planas a suavemente onduladas, ocupadas por bosques bajos de especies leñosas (v.g. Prosopis sp., Acacia sp.) acompañados de sabanas y pastizales (Burkart et al., 1999). No obstante, en la actualidad se encuentra altamente modificada por los efectos de las actividades agropecuarias y de urbanización, por lo que la vegetación típica se ha visto reducida drásticamente en las últimas décadas (Arturi, 2005).

El sitio se emplaza en la cuenca del río Salado, subcuenca del arroyo Cululú, la cual se constituye en una típica cuenca de llanura en la que se destacan eventos hídricos de gran magnitud (Pilatti, 2013). Esta subcuenca comprende dos provincias geomorfológicas: la parte alta corresponde a la Pampa Norte, mientras que el este de la misma -sector donde se localiza AC1 - forma parte del Chaco. En este tipo de ambiente de llanura se dan procesos típicos como inundaciones extendidas en el tiempo, sedimentación generalizada, meteorización profunda y formación de costras (Kröhling y Brunetto, 2013).

Hasta la primera mitad del siglo XIX, el área se mantuvo prácticamente inalterada, conservando aun la vegetación propia del Espinal, con relictos de montes y bosques (Paoli et al., 2013). Posteriormente el área comenzó a ser colonizada por actividad agrícola de bajo impacto, pero hacia la década de 1940 el desarrollo de obras de canalización y de infraestructura (v.g. redes de caminos y parcelamiento de tierras) modificaron sustancialmente el modelo de escurrimiento natural, condicionado por las restricciones naturales de la topografía ( $v$.g. relieve relativamente plano y escasas pendientes) y el tipo de suelos. A esto se le suma un incremento de las precipitaciones anuales luego de la década de 1970, con la aparición de picos de crecidas muy importantes y un aumento de los caudales medios, todo lo cual contribuye a que el sitio se vea afectado por inundaciones periódicas (Paoli, 2004; Paoli et al., 2013).

Las primeras tareas arqueológicas (2016) consistieron en recolecciones de los materiales visibles en superficie y semi-enterrados: fragmentos cerámicos $(n=$ 222) y restos faunísticos $(n=49)$ (ver Galligani et al., 2017). Debido a las intensas crecidas sufridas en la zona, durante el año 2017 el sitio se mantuvo inundado y recién en el mes de diciembre se logró acceder nuevamente (Figura 1B). En esa visita, se mapearon y recolectaron nuevos fragmentos cerámicos y restos óseos humanos semi-enterrados, a una distancia de aproximadamente $40 \mathrm{~m}$ del arroyo Cululú. A partir de estos nuevos hallazgos, se realizaron dos intervenciones, en abril y en septiembre de 2018, en las cuales se recuperaron nuevamente gran cantidad de fragmentos cerámicos y restos faunísticos en superficie y en cinco pozos de sondeo de $0,5 \times 0,5 \mathrm{~m}^{2}$ y $50 \mathrm{~cm}$ de profundidad. Además, se excavaron cinco $\mathrm{m}^{2}$ en dos cuadrículas: una de $2 \times 2 \mathrm{~m}$ (C1) y otra de $1 \times 1 \mathrm{~m}$ (C2), por niveles artificiales de cinco $\mathrm{cm}$, donde se hallaron tres entierros humanos (Figura 2). El sedimento extraído fue cernido en zaranda de malla de $1,5 \mathrm{~mm}$ en agua para la recuperación de todos los materiales.

Hasta el momento el sitio no cuenta con fechados radiocarbónicos ya que, si bien se envió una muestra de un metapodio de Lama sp. para datar mediante AMS a un laboratorio de Estados Unidos, la misma no rindió cantidad suficiente de colágeno. Asimismo, el colágeno extraído de un hueso largo humano exhibió una razón $\mathrm{C} / \mathrm{N}$ fuera de los parámetros considerados normales, incluso de los menos restrictivos (ver Galligani, 2020). 


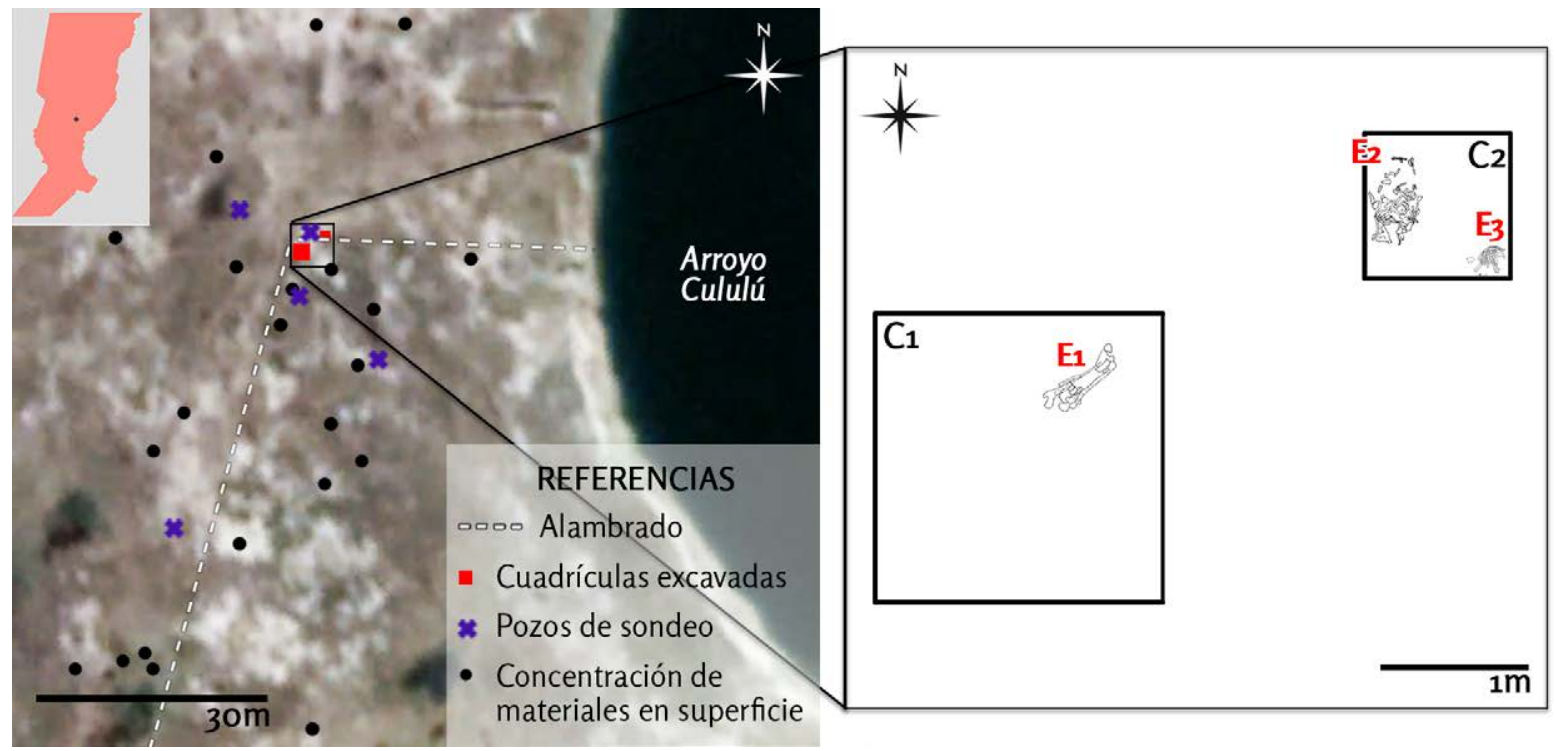

Figura 2. Planta del sitio AC1, localización de los hallazgos y esquema de los entierros humanos recuperados (modificada de Galligani, 2020).

\section{El registro óseo humano}

\section{Materiales y métodos}

En total, se hallaron tres entierros humanos, uno en la cuadrícula 1 (E1) -parte del cual fue descubierto en diciembre de 2017 aflorando en superficie y fue excavado completamente en la primera intervención del año 2018-y dos en la cuadrícula 2 (E2 y E3) -recuperados íntegramente durante las campañas de 2018- (Figura 2). Para su análisis se relevó la ubicación y distribución de los diferentes elementos óseos hallados y se utilizaron Sistemas de Información Geográfica (SIG) para el mapeo de los mismos. En el caso del entierro 3, debido a la fragilidad de los huesos y a la compactación de los sedimentos -y para poder mapearlos con mayor detalle-, se levantó en bloque y se excavó en laboratorio, tomándose fotografías detalladas que registren la ubicación de los elementos.

Se realizó el remontaje, la identificación anatómica, el ensamblaje anatómico entre los elementos de los distintos entierros (para descartar que pertenecieran a un mismo individuo, dado el carácter incompleto de los esqueletos recuperados) y el cálculo de medidas cuantitativas como NISP, NME y NMI (Lyman, 1994, 2008; Mengoni Goñalons, 1999, 2006-2010). Con el objetivo de evaluar el estado de preservación de los huesos se midió la fragmentación de cada conjunto, utilizando el índice de fragmentación propuesto por Mondini (2003) (NME/NISP) -el cual varía entre 0 y 1 , donde los valores cercanos a 1 indican menor fragmentación- y se relevaron diversos efectos postdepositacionales, tales como marcas de raíces y roedores, depositación química de carbonato de calcio $\left(\mathrm{CaCO}_{3}\right)$ y dióxido de manganeso $\left(\mathrm{MnO}_{2}\right)$, hoyos de disolución química y craquelado (Barrientos, Oliva y del Papa, 2002; Barrientos et al., 2007; Galligani, 20120 Gutiérrez, 2004). También se observó la presencia/ausencia de huellas de corte y la localización de las mismas (Buikstra y Ubelaker, 1994). Para el relevamiento de las diferentes variables, la observación se realizó a ojo desnudo y en algunos casos se utilizó una lupa trinocular Mikoba 745 de 50X.

A partir de las observaciones de campo, del mapeo realizado y de las partes presentes y grado de articulación entre las mismas, se infirieron los tipos de entierro representados, considerando dos categorías básicas: entierros primarios y secundarios. Se entiende 
como entierro primario a aquel consistente en la depositación del cadáver sin que medie una cantidad de tiempo significativa entre la muerte del individuo y su inhumación y sin que el cuerpo sea sometido a un tratamiento previo que implique la desarticulación intencional de sus partes (Sprague, 2005; Ubelaker, 1999). El correlato arqueológico de tal práctica es un esqueleto con un alto grado de articulación entre los diferentes elementos anatómicos. Un entierro secundario, por su parte, implica un tratamiento complejo de uno o más cadáveres, con diferentes etapas y en el cual se lleva a cabo - por algún medio - la eliminación de la mayor parte de los tejidos blandos y la desarticulación de los elementos anatómicos. Su correlato arqueológico es la presencia de huesos desarticulados (la totalidad de los elementos anatómicos de un individuo o una selección de los mismos) pero con un agrupamiento y orden global discernible, los cuales pueden presentar algún tipo de decoración (v.g. pintura, grabado) (Goldstein, 1989, 1995; Sprague, 2005; Ubelaker, 1999). Ambos tipos de entierro pueden ser individuales o múltiples. La acción de factores y procesos postdepostacionales (tanto culturales como naturales) pueden, eventualmente, alterar las relaciones espaciales entre los restos, dificultando su correcta identificación. En todos los casos se relevaron datos de interés como la posición, orientación y presencia o ausencia de ajuar funerario o de otros elementos asociados.

A su vez, se realizaron estimaciones de sexo y edad de los individuos, según diferentes criterios, de acuerdo a los elementos óseos disponibles y al estado de preservación de los mismos. En el caso de E1, para la estimación etaria se consideró la fusión epifisiaria de los huesos largos y para la determinación sexual se relevaron dos variables métricas en las epífisis proximales de fémur y húmero: diámetro máximo de la cabeza femoral (FDMC) y diámetro vertical de la cabeza humeral (HDVC) (Buikstra y Ubelaker, 1994). Las medidas fueron tomadas con calibre manual y comparadas con las obtenidas por diferentes autores (Krenzer, 2006; Mazza y Béguelin, 2013) y para el FDMC se aplicó la función discriminante propuesta por Mazza y Béguelin (2013): (FDMC*0,468)21,539. Para la determinación del sexo de E2 se consideraron los rasgos mandibulares: prominencia mentoniana, forma de la arcada dental anterior y eversión de la región del gonion (Buikstra y Ubelaker, 1994; Schutkowski, 1993) y el desgaste dental para la estimación etaria (Lovejoy, 1985). En el caso de E3, un infante, se realizó sólo la estimación etaria mediante criterios cuantitativos -comparando las medidas de las diáfisis de los huesos largos recuperados con aquellas relevadas por Ghantus (1951), Maresh (1970) y Gindhart (1973), citados en Schaefer et al. (2009) - y considerando la erupción dentaria (Ubelaker, 1999).

\section{Resultados}

El NMI calculado fue de tres, por lo que se infiere que, probablemente, en cada entierro se encuentra representado un único individuo. En general, los huesos se encuentran en buen estado de preservación, aunque muy fragmentados, principalmente en E1, que se halló más cercano a la superficie (a $15 \mathrm{~cm}$ de profundidad). El índice de fragmentación del mismo arrojó un valor de 0,13 , mientras que los valores son superiores en el caso de los otros dos entierros (E2 $=0,65 ; E 3=0,81$ ) (Mondini, 2003). Por otro lado, en E1 se registraron dos marcas de roedores, un elemento con depositación de $\mathrm{CaCO}_{3}$ y el $33 \%$ de los huesos con las superficies craqueladas, mientras que en los otros dos entierros no se identificaron estos efectos. Los factores postdepositacionales que actuaron sobre la totalidad del conjunto son las raíces -registrándose el $42 \%$ de los elementos con marcas - y los hoyos de disolución química (40,7\%), mientras que el manganeso se depositó en el $100 \%$ de los huesos de E1 y el $25 \%$ de E3, estando ausente en E2.

En cuanto a los tipos de inhumación, E1, recuperado en la cuadrícula 2, corresponde a un entierro secundario individual compuesto por 12 huesos largos alineados con 
dirección Noreste-Suroeste (Tabla 1 y Figura 3A). No se hallaron huellas visibles de corte ni de manipulación en ninguno de los elementos óseos del mismo. Todas las epífisis presentes estaban fusionadas, indicando que se trata de un individuo adulto. Pudieron tomarse medidas de la cabeza femoral derecha -cuyo diámetro máximo arrojó un valor de $45,4 \mathrm{~mm}$ - y de la cabeza humeral izquierda -diámetro vertical de $46,6 \mathrm{~mm}-$. Estos valores se encuentran dentro de los rangos obtenidos para individuos de sexo masculino (Krenzer, 2006; Mazza y Béguelin, 2013), al igual que el resultado arrojado por la función discriminante aplicada al FDMC $(-0,2918)$. Esto permite asignar el individuo recuperado, con alto grado de probabilidad, al sexo masculino.

\begin{tabular}{|c|c|c|c|c|}
\hline \multirow{2}{*}{ Unidad Anatómica } & \multicolumn{2}{|c|}{ Derecha } & \multicolumn{2}{c|}{ Izquierda } \\
\cline { 2 - 5 } & NISP & NME & NISP & NME \\
\hline Húmero & 3 & 1 & 3 & 1 \\
Cúbito & 9 & 1 & 1 & 1 \\
Radio & 2 & 1 & 3 & 1 \\
Fémur & 17 & 1 & 9 & 1 \\
Tibia & 13 & 1 & 27 & 1 \\
Peroné & 6 & 1 & 1 & 1 \\
\hline
\end{tabular}

Tabla 1. NISP y NME de los restos que componen el entierro secundario hallado en la cuadrícula 1 (E1) del sitio AC1.

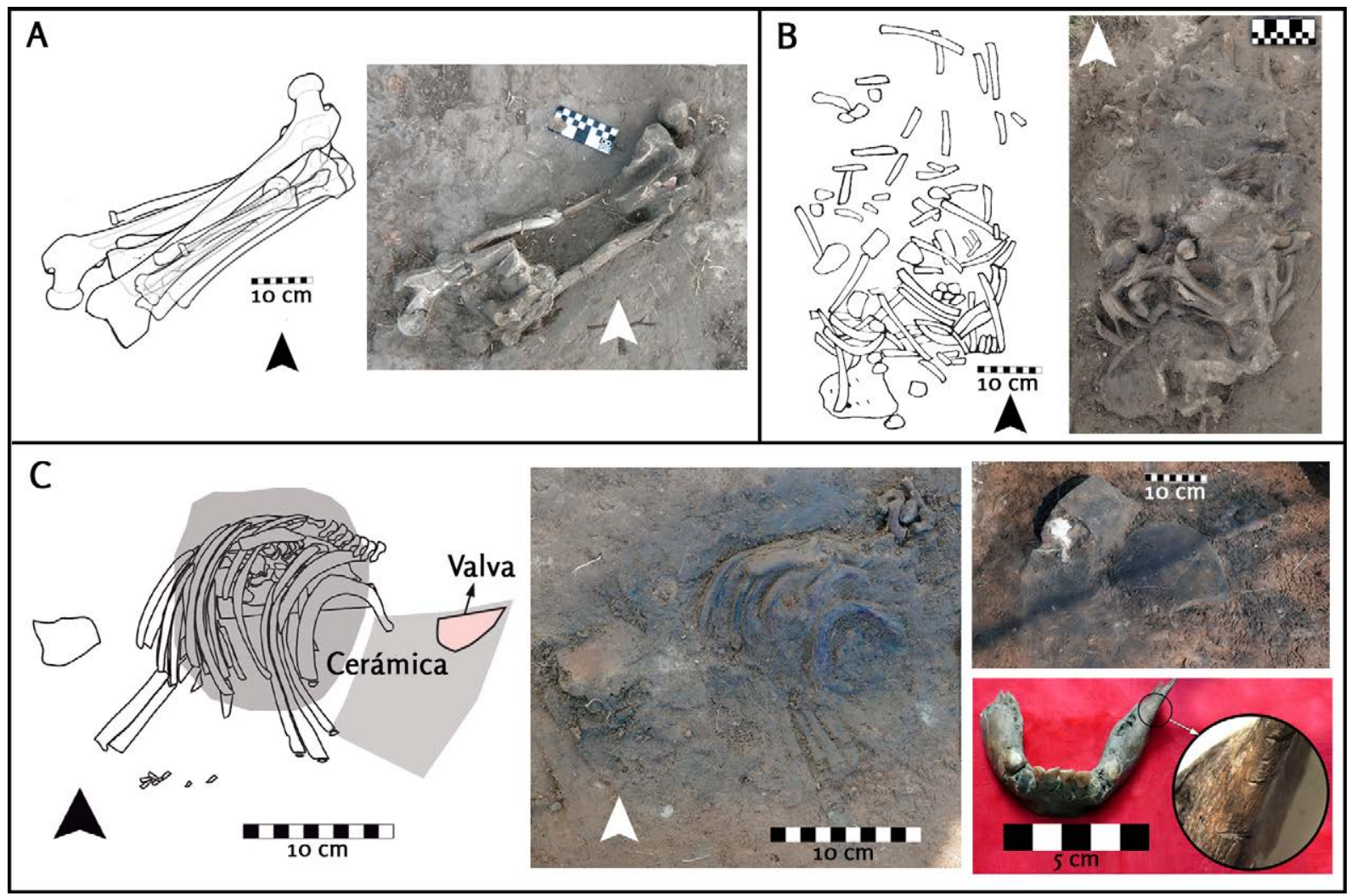

Figura 3. Esquema e imágenes de los entierros recuperados en el sitio AC1: A) entierro 1 (E1); B) entierro 2 (E2); C) entierro 3 (E3), imágenes de la cerámica recuperada sobre el mismo y detalle de las probables huellas de corte identificadas en la mandíbula (modificada de Galligani, 2020). 
E2 también se trata de un entierro secundario individual y se compone de un NME de 31 , encontrándose representados elementos del esqueleto axial (mayoritariamente), de la cintura escapular, costillas y muy pocos elementos del esqueleto apendicular (Tabla 2 y Figura 3B). A diferencia de E1, que muestra una alineación y una orientación clara en la disposición de los huesos, los elementos de E2 se hallaron concentrados en 0,25 $\mathrm{m}^{2}$, hacia el Oeste de la cuadrícula $\mathrm{C} 2$, sin ningún orden ni orientación discernibles. El desgaste dental permite asignar el individuo representado a la categoría adulto (Lovejoy, 1985) y los rasgos mandibulares al sexo femenino (Buikstra y Ubelaker, 1994; Schutkowski, 1993). Al igual que en E1, tampoco se identificaron huellas de corte/ procesamiento ni ajuar funerario asociado.

\begin{tabular}{|c|c|c|c|c|c|c|c|c|}
\hline \multirow{2}{*}{$\begin{array}{c}\text { Unidad } \\
\text { Anatómica }\end{array}$} & \multicolumn{2}{|c|}{ Derecha } & \multicolumn{2}{c|}{ Izquierda } & \multicolumn{2}{c|}{ Axial } & \multicolumn{2}{c|}{ Indet. } \\
\cline { 2 - 8 } & NISP & NME & NISP & NME & NISP & NME & NISP & NME \\
\hline Mandíbula & - & - & - & - & 5 & 1 & - & - \\
Clavícula & 0 & 0 & 1 & 1 & - & - & 0 & 0 \\
Escápula & 2 & 1 & 1 & 1 & - & - & 0 & 0 \\
Costillas & 0 & 0 & 0 & 0 & - & - & $>50$ & $?$ \\
Vértebras torácicas & - & - & - & - & $>50$ & $?$ & - & - \\
Vértebras lumbares & - & - & - & - & 16 & 2 & - & - \\
Vértebras Indet. & - & - & - & - & 18 & $?$ & - & - \\
Sacro & - & - & - & - & $>10$ & 1 & - & - \\
Metacarpo & 1 & 1 & 0 & 0 & - & - & 1 & 1 \\
Falange (mano) & 1 & 1 & 0 & 0 & - & - & 0 & 0 \\
Rótula & 1 & 1 & 0 & 0 & - & - & 0 & 0 \\
Astrágalo & 1 & 1 & 1 & 1 & - & - & 0 & 0 \\
Calcáneo & 1 & 1 & 1 & 1 & - & - & 0 & 0 \\
Navicular & 1 & 1 & 0 & 0 & - & - & 0 & 0 \\
Cuboide & 1 & 1 & 0 & 0 & - & - & 0 & 0 \\
$1^{\circ}$ cuneiforme & 1 & 1 & 0 & 0 & - & - & 0 & 0 \\
$2^{\circ}$ cuneiforme & 1 & 1 & 0 & 0 & - & - & 0 & 0 \\
$3^{\circ}$ cuneiforme & 1 & 1 & 0 & 0 & - & - & 0 & 0 \\
Metatarso & 5 & 5 & 5 & 3 & - & - & 0 & 0 \\
Falange (pie) & 1 & 1 & 0 & 0 & - & - & 2 & 2 \\
\hline
\end{tabular}

Tabla 2. NISP y NME de los restos que componen el entierro secundario adulto (E2) hallado en la cuadrícula 2 del sitio AC1.

Por último, E3 consiste en un conjunto de huesos mayormente articulados, correspondientes al torso y al miembro superior izquierdo de un individuo de corta edad. Sin articulación, se recuperó asimismo el maxilar inferior (en posición invertida) y elementos pertenecientes a ambos pies (Tabla 3 y Figura 3C). El conjunto se encontraba cubierto por un plato de cerámica boca abajo sobre el que se hallaron valvas de Diplodon sp. (ver descripción en el apartado "El Registro Cerámico"). Las partes articuladas indican que se trata de un probable entierro primario, depositado en posición lateral izquierda. En el maxilar inferior, en el borde anterior de la rama izquierda, se detectaron probables marcas de corte, aunque este diagnóstico debe ser confirmado a través de observaciones mediante el uso de microscopia electrónica (Barrientos et al., 2002). Debido a los valores moderadamente alcalinos de los sedimentos $(>10)$, al carbonato 
aportado por las valvas y a la protección proporcionada por el plato de cerámica que cubría los restos, es poco probable que la ausencia de partes esqueletarias obedezca a razones diagenéticas o a otros factores o procesos postdepositacionales. Una de las posibilidades es que se trate de un individuo que fue enterrado con pérdida previa de partes del cuerpo debido o bien a alguna práctica cultural desconocida (poco probable) o a que se encontraba en un avanzado estado de descomposición al momento de la inhumación. Las medidas de los huesos largos (húmero $=11 \mathrm{~cm}$; cúbito $=9,6 \mathrm{~cm}$; radio $=8,6 \mathrm{~cm}$ ), junto con el grado de erupción dentaria, permitieron estimar una edad probable de entre 12 y 18 meses (Schaefer et al., 2009).

\begin{tabular}{|c|c|c|c|c|c|c|c|c|}
\hline \multirow{2}{*}{$\begin{array}{c}\text { Unidad } \\
\text { Anatómica }\end{array}$} & \multicolumn{2}{|c|}{ Derecha } & \multicolumn{2}{c|}{ Izquierda } & \multicolumn{2}{c|}{ Axial } & \multicolumn{2}{c|}{ Indet. } \\
\cline { 2 - 9 } NISP & NME & NISP & NME & NISP & NME & NISP & NME \\
\hline Mandíbula & - & - & - & - & 1 & 1 & - & - \\
Clavícula & 1 & 1 & 1 & 1 & - & - & 0 & 0 \\
Escápula & 2 & 1 & 2 & 1 & - & - & 0 & 0 \\
Costillas & 0 & 0 & 0 & 0 & - & - & $>50$ & $?$ \\
Atlas & - & - & - & - & 2 & 1 & - & - \\
Axis & - & - & - & - & 3 & 1 & - & - \\
Vértebras cervicales & - & - & - & - & 6 & $?$ & - & - \\
Vértebras torácicas & - & - & - & - & 23 & $?$ & - & - \\
Vértebras lumbares & - & - & - & - & 9 & $?$ & - & - \\
Vértebras Indet. & - & - & - & - & 20 & $?$ & - & - \\
Húmero & 0 & 0 & 2 & 1 & - & - & 0 & 0 \\
Cúbito & 0 & 0 & 1 & 1 & - & - & 0 & 0 \\
Radio & 0 & 0 & 1 & 1 & - & - & 0 & 0 \\
Metacarpo & 0 & 0 & 0 & 0 & - & - & 4 & 4 \\
Ilion & 1 & 1 & 0 & 0 & - & - & 0 & 0 \\
Metatarso & 5 & 5 & 5 & 5 & - & - & 0 & 0 \\
Falange (pie) & 0 & 0 & 0 & 0 & - & - & 1 & 1 \\
\hline
\end{tabular}

Tabla 3. NISP y NME de los restos que componen el entierro del infante (E3) hallado en la cuadrícula 2 del sitio AC1.

\section{El registro arqueofaunístico}

\section{Materiales y métodos}

La muestra de $\mathrm{AC} 1$ se compone de 98 especímenes, de los cuales 49 fueron recuperados en las intervenciones realizadas en el sitio durante el año 2016 (ver Galligani et al., 2017), en tanto que los restantes fueron recuperados durante las campañas de 2017 y 2018. Considerando el grado de fragmentación, un $65 \%$ de los especímenes no pudieron ser asignados a categorías específicas. Los huesos se hallaron mayoritariamente -al igual que el registro cerámico- dispersos en superficie o semi-enterrados. Sólo dos elementos provienen de dos pozos de sondeos realizados en sectores en los cuales se detectaron concentraciones de materiales cerámicos. 
Teniendo en cuenta este contexto, el análisis arqueofaunístico estuvo dirigido, en primera instancia, a identificar los procesos tafonómicos intervinientes en la preservación del conjunto. En segundo lugar, se buscó conocer la composición taxonómica para poder establecer las especies potencialmente explotadas. Con estos objetivos, se realizó la identificación a nivel anatómico e intentando alcanzar el mayor nivel taxonómico posible. La cuantificación se llevó a cabo a través de las medidas de abundancia utilizadas tradicionalmente (NISP, NMI y NME) (Lyman, 1994, 2008; Mengoni Goñalons, 1999, 2006-2010).

En cuanto al relevamiento de los agentes/procesos tafonómicos se observó la presencia de meteorización (Andrews, 1990; Behrensmeyer, 1978), marcas de roedores y raíces, la depositación química de dióxido de manganeso y carbonato de calcio e indicios de abrasión, vinculada con la acción sedimentaria o el transporte fluvial (Gutiérrez, 2004; Gutiérrez y Kauffman, 2007). Por último, se relevaron las modificaciones antrópicas que sufrieron los especímenes producto de su procesamiento, entre las cuales se consideraron huellas de corte, fracturas y alteraciones térmicas (Lyman, 1994; Mengoni Goñalons, 1999). Para la observación de tales atributos se utilizó una lupa trinocular Mikoba 745 de 50X.

\section{Resultados}

La muestra está compuesta exclusivamente por mamíferos, dentro de los cuales predominan aquellos que son mamíferos grandes pero que no pudieron ser determinados a nivel específico (Tabla 4). La especie más representada, en términos de NISP es Cavia aperea, de la cual se recuperaron mayormente elementos craneales, que pertenecen al menos a tres individuos. El otro roedor identificado es Myocastor coypus, sólo representado por un fragmento de fémur.

\begin{tabular}{|c|c|c|c|}
\hline Taxa & NISP & NISP (\%) & NME \\
\hline Mammalia & 24 & 24,5 & 21 \\
Mammalia grande & 28 & 28,6 & 27 \\
Mammalia mediano & 12 & 12,2 & 10 \\
Artiodactyla & 1 & 1 & 1 \\
Lama sp. & 7 & 7,2 & 4 \\
Ozotoceros bezoarticus & 3 & 3 & 3 \\
Myocastor coypus & 1 & 1 & 1 \\
Cavia aperea & 14 & 14,4 & 14 \\
Dasypodidae & 2 & 2 & 2 \\
Ave & 2 & 2 & 1 \\
Indet. & 4 & 4,1 & 4 \\
\hline Total & $\mathbf{9 8}$ & $\mathbf{1 0 0}$ & $\mathbf{8 8}$ \\
\hline
\end{tabular}

Tabla 4. Medidas cuantitativas del conjunto faunístico recuperado en el sitio AC1.

Entre los artiodáctilos el más abundante es Lama sp., representado por elementos del esqueleto apendicular: fémur, metatarsos (un fragmento proximal y uno distal) y astrágalo (Figura 4). Este taxón es el único que evidencia señales de alteración por acción humana, registrándose una fractura helicoidal en un metapodio (Galligani et al., 2017). También se identificaron tres elementos de Ozotoceros bezoarticus: húmero, tibia y falange (Figura 4). 

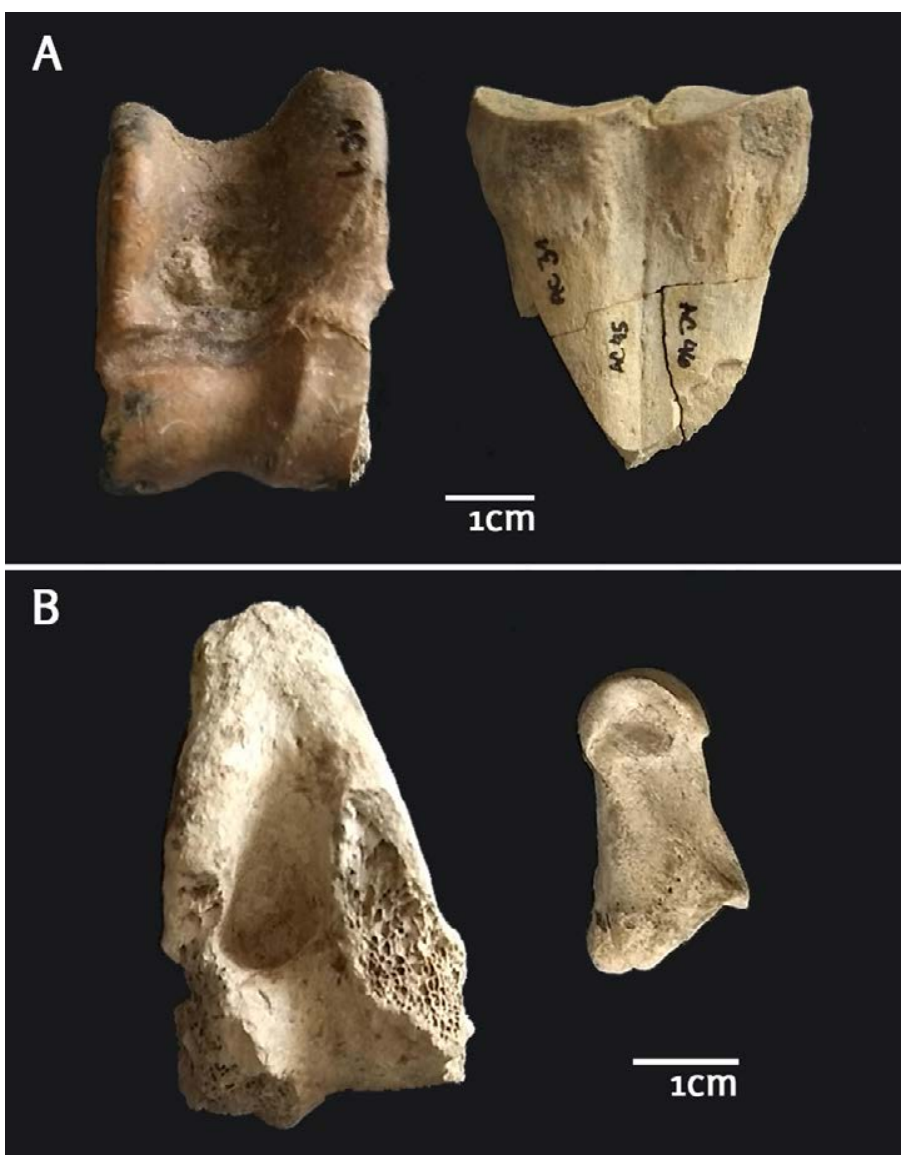

Figura 4. Elementos arqueofaunísticos recuperados en el sitio AC1: A) astrágalo y metatarso de Lama sp.; B) húmero y falange de Ozotoceros bezoarticus (modificada de Sartori, Galligani y Balducci, 2019).

En cuanto a los taxa con menor representación, se hallaron dos elementos correspondientes a la familia Dasypodidae (una falange y un calcáneo) y un húmero de ave. Este último elemento es probable que haya permanecido semi-enterrado y con una exposición relativamente breve, debido a la buena preservación superficial y a la ausencia de efectos de meteorización, al igual que sucede con los restos de cávidos. No se descarta que su asociación con el registro arqueológico del sitio se deba a causas naturales, propias de los procesos postdepositacionales que actuaron en la formación del conjunto.

Los materiales arqueofaunísticos recuperados muestran distintas señales de alteración que se vinculan con el contexto de depositación del registro. En este sentido lo que predominan son las marcas de raíces, presentes en un $53 \%$ de la muestra. Las mismas se observan con un patrón dendrítico que tiñe levemente la superficie de los materiales de un color marrón claro. Esto es coincidente con lo registrado en campo, en donde muchos de los materiales se observaban "entrampados" entre las gramíneas. También en algunos casos se registran surcos pronunciados que habrían sido producidos por raíces de árboles de gran porte. Las marcas de roedores habrían afectado escasamente al registro ya que están presentes en un solo elemento, un húmero de Ozotoceros bezoarticus.

En cuanto a la meteorización, cabe señalar que los elementos que corresponden a fauna mayor son aquellos que presentan los estadios más altos (hasta un grado 3 - 4; sensu Behrensmeyer, 1978), mientras que los mamíferos pequeños, como los cávidos, 
exhiben estadio 0 (sensu Andrews, 1990). Las manchas de manganeso son visibles en un $1 \%$ de la muestra y se presentan en formas de puntos o concentraciones que tiñen el tejido cortical. Sólo se registró depositación de carbonato de calcio -la cual es escasa y muy localizada- en un sector del astrágalo de Lama sp. Los especímenes correspondientes a esta especie no muestran evidencias de meteorización, a diferencia de lo que ocurre con los elementos de Ozotoceros bezoarticus, en los que se registró un estadio 2. Sí en cambio tres de los materiales de Lama sp. presentan el pulido característico de la abrasión sedimentaria.

No pudieron detectarse huellas de corte, lo cual puede deberse a que los elementos no presentan este tipo de alteración producto de la actividad humana, o que la intensidad de las marcas de raíces, sumado a la meteorización, las hayan enmascarado. Se pudo determinar una sola fractura helicoidal antrópica, en un fragmento de metatarso de Lama sp. Las alteraciones térmicas se encuentran presentes en un $8,1 \%$, dentro del cual cinco especímenes se hallan calcinados y tres quemados. Los elementos termoalterados corresponden a fragmentos de diáfisis de huesos largos de Mammalia mediano.

\section{El registro cerámico}

\section{Materiales y métodos}

Los tiestos cerámicos recuperados en las tareas arqueológicas realizadas durante 2017 y 2018 en AC1 ascienden a 1.569, los cuales, sumados a los 222 fragmentos recolectados en el año anterior, arrojan un total de 1.791. A los efectos de este trabajo, se excluyeron aquellos menores a $1,5 \mathrm{~cm}$ de longitud máxima, dado que no permitieron la observación de la mayoría de los atributos a relevar. En consecuencia, la muestra analizada se compone de 1.271 fragmentos. En general, la evaluación se realizó macroscópicamente, excepto para el relevamiento de ciertos caracteres, para los que se utilizó una lupa trinocular Mikoba 745 (50X). Además, se realizaron tareas de remontajes, previas al análisis, dada la cantidad de fragmentos con evidencias de fracturas frescas.

En primera instancia se consideraron una serie de atributos vinculados con cuestiones tafonómicas generales: tipos y grados de abrasión (Schiffer y Skibo, 1989), distinguiendo entre efecto pedestal (Sanhueza Riquelme, 1998; Skibo, 1987), agrietamiento (García Roselló y Calvo Trías, 2006; Schiffer y Skibo, 1989), laminación (Schiffer y Skibo, 1989) y redondeamiento (Sanhueza Riquelme, 1998); presencia/ausencia de residuos orgánicos (García Roselló y Calvo Trías, 2006; Skibo, 1992), depositación química de dióxido de manganeso (Daniels, 1981) y sales (Fernández Ibañez, 2003); marcas de raíces (Behrensmeyer, 1978) y de roedores (Gutiérrez, 2004).

Posteriormente, se asignó cada fragmento a una parte específica de la vasija, siguiendo los criterios propuestos por Balfet, Fauvet Berthelot y Monzón (1992): cuerpo, borde, base, asa y apéndices. Asimismo, se registraron atributos que aportan información sobre la atmósfera de cocción de las piezas, su impermeabilidad, maleabilidad, entre otros: presencia/ausencia de inclusiones y color en las superficies (interna-externa), los márgenes (interno-externo) y en el núcleo de cada tiesto (Banning, 2000; Convención Nacional de Antropología, 1966; Cremonte y Bugliani, 2006-2009; García Rosselló y Calvo Trías, 2006; Rye, 1981). Por otra parte, se relevaron una serie de variables relacionadas con el tratamiento general de las superficies (internas y externas) que, en sentido amplio, se vinculan con aspectos decorativos y funcionales: baño/ engobe, alisado, pulido, pintura, incisión, impronta de textiles (Convención Nacional de Antropología, 1966; Cremonte y Bugliani, 2006-2009; González y Frère, 2010). 


\section{Resultados}

Los tiestos remontados ascienden a 470, mayormente a partir de las evidencias de fracturas frescas recientes que presentaban los mismos. Generalmente, se logró unir entre sí a dos, tres o cuatro fragmentos, llegándose en muy pocos casos a la unión de nueve, 10 o hasta 20 fragmentos en una sola pieza, como es el caso del plato cerámico recuperado en el entierro 3 (Figura 5B).

Gran parte del material cerámico presenta alteraciones que pueden influir en el registro de otras variables. En este sentido, el 37,1\% de los materiales evidenciaron algún grado de redondeamiento y el $35,7 \%$ muestra abradidas sus superficies, relevándose efecto pedestal en un $6 \%$. También se registró agrietamiento en un $22,9 \%$ de los tiestos y delaminación en un $13,5 \%$. Se observaron, además, marcas de raíces en un $5,3 \%$, mientras que las marcas generadas por roedores se relevaron sólo en un 3,2\%. En cuanto a las depositaciones químicas, el dióxido de manganeso afectó la muestra en un $7,8 \%$, las sales en un $0,6 \%$ y se registraron residuos orgánicos en forma de hollín en un $2,1 \%$.

En relación con las partes de los contenedores cerámicos, los fragmentos fueron asignados en mayor proporción a la categoría cuerpo $(83,2 \%)$, seguidos por bordes $(12,5 \%)$ y, con menor frecuencia, bases $(3,9 \%)$, asas $(0,3 \%)$ y un apéndice zoomorfo que representa a un ave $(0,1 \%)$ (Figura $5 \mathrm{~A}$ y $5 \mathrm{C}$ ).

La presencia de inclusiones de tiesto molido se registró en un $88,2 \%$ de la colección, observándose con menor asiduidad otros elementos como mica y partículas biosilíceas. A partir del color de los fragmentos en sus distintos sectores, puede inferirse que la atmósfera de cocción fue principalmente reductora $(64,7 \%)$, seguida de parcialmente oxidante $(31,8 \%)$ y oxidante $(3,5 \%)$.

Los resultados de las variables vinculadas con los tratamientos superficiales se presentan en forma sintética en la Tabla 5. La alfarería del sitio AC1 es fundamentalmente

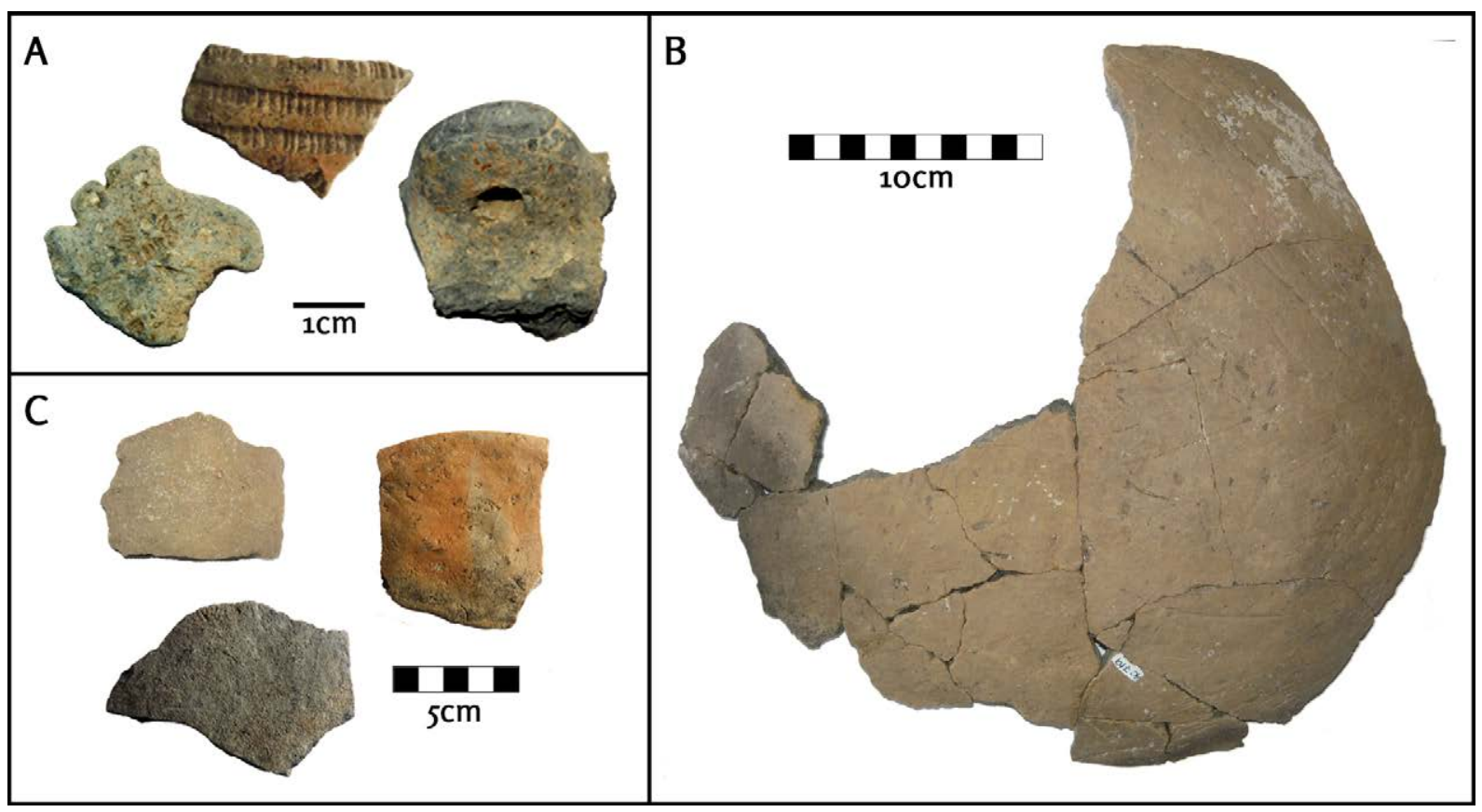

Figura 5. Cerámicas recuperadas en AC1: A) apéndice zoomorfo, fragmento con incisos y asa; B) plato de cerámica recuperado junto con el entierro del infante; C) tiestos lisos. 
lisa $(97,2 \%)$, hallándose escasos porcentajes de tiestos con decoración incisa $(1,9 \%)$ -mayormente en la cara externa de los fragmentos - e improntas textiles $(0,9 \%)$-en la superficie interna en todos los casos-. Respecto del tipo de inciso, prevalece el surco rítmico en el cuerpo de los fragmentos ( $47,3 \%$ de los casos analizados), seguido de incisión de punto (18,4\%) y de línea (10,5\%); mientras que en el labio del borde sólo se halla identificada la incisión de línea. Se observa la presencia de baño/engobe en un $55,2 \%$ del conjunto analizado, siendo menor la representación de alisado $(15,2 \%$ y de pulido (1,1\%). En el caso del baño/engobe, fue identificado con mayor frecuencia en la cara externa de los fragmentos, en tanto que el alisado y el pulido fueron relevadas en proporciones similares en ambas superficies. Por último, en relación a la pintura, solo un $0,8 \%$ del total de la muestra evidencia rastros de este tipo de tratamiento, exclusivamente de color rojo y mayormente en la parte interna de los fragmentos.

\begin{tabular}{|c|c|c|c|c|c|c|c|c|}
\hline \multirow{2}{*}{ Tratamiento Superficial } & \multicolumn{2}{|c|}{$\begin{array}{c}\text { Superficie } \\
\text { Interna }\end{array}$} & \multicolumn{2}{c|}{$\begin{array}{c}\text { Superficie } \\
\text { externa }\end{array}$} & \multicolumn{2}{c|}{$\begin{array}{c}\text { Ambas } \\
\text { superficies }\end{array}$} & \multicolumn{2}{c|}{$\begin{array}{c}\text { Total de } \\
\text { presencias }\end{array}$} \\
\cline { 2 - 9 } & $\mathbf{n}$ & $\%$ & $\mathbf{n}$ & $\%$ & $\mathbf{n}$ & $\%$ & $\mathbf{n}$ & $\%$ \\
\hline Engobe & 139 & 10,94 & 199 & 15,66 & 364 & 28,64 & 702 & 55,23 \\
Alisado & 85 & 6,69 & 74 & 5,82 & 35 & 2,75 & 194 & 15,26 \\
Pulido & 5 & 0,39 & 5 & 0,39 & 2 & 0,16 & 14 & 1,10 \\
Pintura & 9 & 0,71 & 1 & 0,08 & 0 & 0,00 & 10 & 0,79 \\
Inciso & 4 & 0,31 & 18 & 1,42 & 2 & 0,16 & 24 & 1,89 \\
Impronta Textil & 12 & 0,94 & 0 & 0,00 & 0 & 0,00 & 12 & 0,94 \\
\hline
\end{tabular}

Tabla 5. Frecuencias y porcentajes de presencia de las variables de tratamiento superficial en los fragmentos cerámicos del sitio AC1. Los porcentajes fueron calculados sobre el total del conjunto $(N=1.271)$.

De particular interés resulta el hallazgo de gran parte de un plato cerámico cubriendo al entierro del infante (E3) en la cuadrícula C2 (Figuras 3C y 5B). Es de destacar que el mismo se encontraba fragmentado, y sus tiestos estaban dispersos en un diámetro de alrededor de $40 \mathrm{~cm}$, no hallándose fragmentos correspondientes al borde. En laboratorio se realizaron tareas de remontaje, lográndose unir 20 fragmentos, los cuales no presentaban indicios de fracturas frescas actuales. Las medidas son: $26,9 \mathrm{~cm}$ de longitud máxima por $23,7 \mathrm{~cm}$ de ancho por $0,7 \mathrm{~cm}$ de espesor promedio. No obstante, existen otros tiestos con fracturas frescas que no pudieron ser remontados pero que poseen características similares, por lo que probablemente pertenezcan al mismo contenedor. En cuanto a la preservación, el plato se halla poco abradido, con algunos signos de agrietamiento, marcas de raíces y se puede observar la depositación de hollín y de sales en diferentes sectores de ambas superficies.

\section{Discusión}

Los proyectos de investigación que se vienen realizando desde el año 2015 en el área de confluencia del río Salado y el arroyo Cululú comenzaron a arrojar luz sobre una zona que prácticamente carecía de información arqueológica sistemática, a pesar del gran potencial que sugerían los trabajos pioneros de principios del siglo pasado (v.g. Castellanos, 1924; Frenguelli, 1920; Vignati, 1923, 1931, 1934) y los posteriores realizados por Ceruti $(1988,1995)$. Particularmente las intervenciones llevadas a cabo en el sitio AC1 en los últimos años, dieron como resultado el hallazgo de una importante cantidad y variedad de materiales arqueológicos, cuyo análisis integral - que abarca a los distintos elementos del registro- permite comprender diferentes 
aspectos vinculados a los procesos de formación de sitio y también a las prácticas culturales del pasado.

Uno de los problemas más acuciantes que presenta el sitio, como se ha mencionado, es la dinámica hídrica actual, generada, entre otros factores, por la construcción de canales artificiales y el aumento de las precipitaciones anuales, lo que produce que el acceso al mismo esté inhabilitado durante lapsos más o menos prolongados de tiempo. Las inundaciones sufridas periódicamente inciden, a su vez, en la preservación del registro arqueológico ya que, al lavarse el horizonte superficial del suelo, los materiales arqueológicos quedan expuestos a agentes y procesos que los afectan en términos superficiales, macroscópicos y también desde el punto de vista de su fragmentación, distribución, dispersión y re-depositación (v.g. acción del ganado vacuno)

Esta dinámica del ambiente de depositación -vinculada con la acción del agua y al movimiento e impacto de sedimentos fluviales y elementos que estos transportan ( $\mathrm{v} . \mathrm{g}$. sales, manganeso) - se refleja en los efectos registrados en los diferentes materiales recuperados en superficie y semi-enterrados: depositación química, fragmentación, redondeamiento, abrasión, agrietamiento, entre otros. En el caso de los huesos hallados en estratigrafía (entierros humanos), principalmente aquellos que no presentaban elementos expuestos semi-superficialmente (E2 y E3), exhiben un buen estado de preservación macroestructural, en comparación con los hallados en otros sitios de la cuenca Salado-Coronda (v.g. Río Salado-Coronda II, Familia Primón; ver Galligani, 2020; Galligani et al., 2019). Si bien es evidente la acción de algunos agentes que afectaron la generalidad del registro ( $v$.g. marcas de raíces, fracturas por presión de sedimento y/o pisoteo), el conjunto óseo humano permitió su remontaje y la realización de análisis bioarqueológicos (v.g. estimación sexo-etaria), hasta el momento difíciles de concretar sobre restos de otros sitios de la zona mencionada.

Sin embargo, si bien los entierros humanos se han hallado en estratigrafía, los mismos aparecen a una profundidad máxima de $30 \mathrm{~cm}$. De acuerdo con Ceruti (1995), los sitios arqueológicos ubicados en este sector de la cuenca del Salado se caracterizan por materiales que suelen aparecer en superficie y en las cercanías de las márgenes de los cauces de agua. Hasta el momento este parece ser el caso del sitio AC1, cuyos materiales provienen mayormente de recolecciones superficiales realizadas a escasos metros de la margen derecha del arroyo Cululú, con excepción de las inhumaciones descriptas. No obstante, no se descarta la posibilidad de que puedan hallarse mayor cantidad y variedad de materiales en estratigrafía en futuras excavaciones.

El hallazgo de inhumaciones en las últimas intervenciones permite acercarse al conocimiento de un aspecto nuevo del sitio, como un área de entierros. En ella se han identificado, hasta el momento, tres modalidades mortuorias diferentes, en una distancia máxima de tres metros: dos entierros secundarios individuales -uno compuesto de huesos largos alineados con orientación Noreste-Sudoeste y otro por un conjunto de elementos sin una disposición y orientación claras- $-y$ un entierro primario de un infante. En otros sitios arqueológicos localizados en el área del Paraná medio e inferior se han registrado inhumaciones con ajuar de cerámica y/o valvas de Diplodon sp., similares a las identificadas en AC1 (v.g. Ceruti, 1988; Cocco, 2004; Cornero, 1999; Feuillet Terzaghi, 2009; Mazza y Loponte, 2012; Scabuzzo, Ramos van Raap, Bonomo y Politis, 2015). Sin embargo, no se ha registrado ningún entierro primario de infante con las características del hallado, i.e. un individuo incompleto, sin cráneo, depositado su torso en posición lateral izquierda, con ajuar funerario directamente asociado, consistente en un plato de cerámica dispuesto de modo que cubría completamente el cuerpo. En este sentido, resta evaluar qué sucede con esta modalidad de entierro en otras regiones colindantes, como Chaco o Sierras Centrales. 
Respecto del estudio del registro arqueofaunístico de $\mathrm{AC} 1$, el mismo constituye uno de los pocos análisis sistemáticos realizados sobre sitios del interior de la provincia de Santa Fe, lo que resulta relevante, ya que este tipo de investigaciones se ha visto circunscripto casi exclusivamente a sitios vinculados con la llanura aluvial del río Paraná (LLAP) (ver discusión al respecto en Sartori, Colasurdo y Santiago 2014; Sartori, Santiago y Colasurdo, 2017). Es así como los resultados obtenidos generan nueva información en un doble sentido: por un lado, arrojan luz sobre el tipo de explotación faunística en ambientes del Espinal santafesino y, por otro, aportan datos que pueden ser incorporados dentro de las discusiones regionales acerca del uso del espacio y los recursos disponibles.

La tendencia de la composición faunística observada en la primera intervención al sitio se mantuvo en las tareas subsiguientes (ver Galligani et al., 2017), evidenciándose nuevamente la baja proporción de restos arqueofaunísticos en relación con los demás materiales arqueológicos recuperados ( $v$.g. tiestos cerámicos). Esto probablemente esté vinculado con los procesos cíclicos de inundación que afectan al sitio desde, al menos, los últimos 60 años, aunque resta sondear en lugares más alejados del área de entierros (v.g. monte de leñosas), la cual aún no está delimitada.

Si bien el conjunto es pequeño (ya que se debe seguir explorando el sitio en intervenciones futuras), hay algunas tendencias que pueden derivarse del análisis arqueofaunístico. Por un lado, al registro previo de Lama sp. (Galligani et al., 2017), se suma la identificación de Ozotoceros bezoarticus, ambos recursos típicos de ambientes abiertos y no anegados. Si bien las representaciones de ambos son bajas, es probable que muchos fragmentos de mamíferos grandes/medianos correspondan a estos taxa. En términos de NISP, Lama sp. es uno de los recursos mejores representados en el conjunto y uno de sus elementos es el único que presenta posibles huellas de fractura antrópica. Cabe señalar que este taxón, ausente en la región desde, al menos, momentos históricos, es el que predomina en otros sitios de la región Pampeana y que ha sido propuesto como central en la subsistencia de los grupos que habitaron el centro y sur del actual territorio santafesino (ver Ceruti, 1987; Cornaglia Fernández, 2012).

Por su parte, Ozotoceros bezoarticus también ha sido señalado como un recurso de importancia, fundamentalmente en sitios arqueológicos continentales -no insulares-, y es una especie que, actualmente, se halla casi extinta en la provincia, reducida a pequeñas comunidades en el norte de la misma (Pautasso, Peña, Mastropaolo y Moggia, 2002; Sartori et al., 2017). Si bien en este caso los materiales no presentan huellas antrópicas, es posible que éstas se vean enmascaradas por los procesos postdepositacionales ya que, a diferencia de lo que ocurre con Lama sp., todos los materiales de esta especie provienen de superficie y presentan señales de meteorización.

Una particularidad que se mantiene es la ausencia de peces y la baja representación de Myocastor coypus, a pesar de que el sitio se encuentra muy cerca de los cursos de agua, por lo que estos recursos habrían estado disponibles. El predominio de mamíferos de mediano/gran porte sobre aquellos acuáticos, como los peces y el coipo, podría sugerir elecciones en la explotación de recursos terrestres vinculados al ambiente del Espinal. En cuanto a los taxa que actualmente abundan en la zona (como los cávidos, dasipódidos y las aves) no se descarta que algunos elementos no provengan del contexto arqueológico, motivo por el cual las actividades venideras servirán para contrastar mejor la información obtenida del registro subsuperficial y de observaciones ambientales de interés tafonómico. Si bien debe esperarse a contar con mayor cantidad de materiales y, preferentemente, provenientes de diferentes sitios del área, es interesante observar las tendencias que comienzan a delinearse (Sartori et al., 2019). Estas tendencias muestran un contraste con otros ambientes fluviales de 
la LLAP, donde Lama sp. se encuentra totalmente ausente en todos los registros de sitios insulares y, por el contrario, predominan los recursos vinculados a los ambientes acuáticos (fundamentalmente peces y Myocastor coypus) (Sartori et al., 2017).

Respecto del registro cerámico, los resultados obtenidos en este trabajo refuerzan las observaciones realizadas en las investigaciones de Frenguelli (1920) y de Ceruti (1987, 1988) y algunas consideraciones efectuadas previamente en Galligani et al. (2017), en lo que refiere a sus características generales. En este sentido, la alfarería de los grupos cazadores-recolectores-pescadores que habitaron la zona exhibe rasgos similares a la de otros sitios ubicados en la llanura chaco-pampeana del centro santafesino, como por ejemplo la predominancia de fragmentos lisos, el tipo de cocción y de decoración, la presencia de improntas textiles, entre otros (ver Ceruti, 1988, 2000).

Por una parte, Ceruti (1988) ha sugerido que existe una tendencia progresiva, en la cual se observa una mayor temperatura alcanzada en la cocción de los contenedores, que sigue un vector este-oeste desde el río Paraná (ver Ceruti, 1988). A partir de los colores visibles en el núcleo, márgenes y superficies de los tiestos de $A C 1$, se puede inferir que la cocción de la cerámica se realizó en una atmósfera predominantemente reductora, aunque se registran porcentajes significativos de atmósferas parcialmente oxidantes y oxidantes, que son levemente superiores a los identificados en otros sitios de zonas vinculadas a la LLAP (v.g. Familia Primón, Los Bañados, Las Tejas, Pajas Blancas) (Balducci, 2021).

En relación con los tratamientos superficiales, al igual que lo observado por Frenguelli (1920) y Ceruti (1988), se destaca que los fragmentos son fundamentalmente lisos ( $97,2 \%$ del total), con escasa presencia de tiestos con decoración incisa e improntas textiles (cestería, redes y cordelería). Estas últimas son un aspecto singular en los modos de hacer de este conjunto, rasgo que aumenta su frecuencia en los conjuntos cerámicos a medida que nos desplazamos hacia los actuales territorios de las provincias de Chaco, Córdoba y Santiago del Estero (Balducci, Sartori, Frère y González, 2019). En cuanto a las técnicas de incisión, si bien son escasas, se observa la predominancia de surco rítmico, el cual es uno de los rasgos típicos de los conjuntos cerámicos de grupos cazadores-recolectores-pescadores de los tramos medios e inferior del río Paraná y el sector inferior del río Uruguay, al igual que la presencia de apéndices zoomorfos similares al recuperado en AC1 (Figura 5A) (Bonomo et al., 2016; Di Prado y Castro, 2014; Gascue et al., 2019; Ottalagano, 2016; Pérez, 2016, entre otros).

Por otro lado, la cantidad de fragmentos con evidencias de engobe apenas supera la mitad de la muestra, mientras que aquellos con rasgos de alisado y pulido, y con rastros de pintura, es exigua. Sin embargo, como se ha mencionado también para el registro arqueofaunístico, se debe tener en cuenta que los materiales estuvieron expuestos a diferentes agentes erosivos -sedimentarios e hídricos- que provocaron su deterioro, haciendo que probablemente se subestimen las frecuencias de presencia de dichas variables. Por lo tanto, consideramos que para realizar interpretaciones sobre estos atributos resulta indispensable recuperar un mayor porcentaje de materiales en estratigrafía, cuya preservación superficial se vea menos afectada.

Finalmente, como ya se ha enunciado, hasta el momento el sitio no cuenta con dataciones radiocarbónicas, ni sobre restos humanos ni sobre huesos arqueofaunísticos. Por este motivo no se puede aseverar que se trate de una sola ocupación y que los entierros sean contemporáneos, a la vez que las comparaciones con otras evidencias de ocupación de la zona están limitadas temporalmente. En este sentido, resta continuar con los estudios diagenéticos en curso, vinculados con la preservación del colágeno, para profundizar en el conocimiento de aquellos factores y procesos que inciden sobre los materiales óseos y que impiden lograr dataciones confiables, ya que la mala 
preservación del colágeno no sólo afecta a este sitio, sino que se trata de un problema de escala regional (Galligani, 2020).

\section{Consideraciones finales}

En este trabajo se analizaron los diferentes materiales arqueológicos en relación con su contexto de depositación, aspecto relevante que permite comprender la formación del conjunto para luego realizar inferencias de carácter cultural. Las inundaciones periódicas que afectan a AC1 comprometen la preservación del registro arqueológico, ya que erosionan el horizonte superficial del suelo dejando a gran parte de los materiales expuestos a agentes y procesos que actúan con diferente intensidad y producen su deterioro/destrucción parcial o total.

No obstante, se destaca el hallazgo de algunos materiales, específicamente los entierros humanos recuperados en estratigrafía, en buen estado de preservación, característica excepcional en la zona de estudio. Esto abre un nuevo panorama que posibilitará, a futuro, comenzar a profundizar en los estudios bioarqueológicos, específicamente en cuestiones vinculadas con las dinámicas demográficas, poblacionales y de saludnutrición de los grupos que habitaron la zona en el pasado, las cuales suelen ser complejas de abordar por el estado de conservación de los conjuntos. Resta también realizar análisis específicos con microscopía de barrido para confirmar si las huellas halladas en uno de los entierros son efectivamente de corte.

Por otra parte, los nuevos hallazgos aportan información novedosa sobre el centro de la provincia de Santa $\mathrm{Fe}$, un área poco estudiada desde un punto de vista arqueológico y que es, tanto geográfica como ecológicamente, diferente a la llanura aluvial del río Paraná, la cual cuenta con una amplia trayectoria y diversidad de investigaciones. Esto permitirá indagar acerca del modo de vida, el uso del espacio, el aprovechamiento de los recursos y los modos de hacer de las poblaciones humanas del pasado e incluir esta área en los debates que se están generando dentro de la arqueología de la región.

\section{Agradecimientos}

A Fabián Brunas y Hugo Galimberti por permitirnos el ingreso al establecimiento donde se emplaza el sitio cada vez que así lo requerimos. A Yolanda y Rita de la casa de retiro "Santa Catalina" por su buen recibimiento. Al Dr. Gustavo Barrientos, al Lic. Víctor Martínez Quiroz y a las integrantes del grupo de investigaciones por su participación en las campañas de 2018. A los evaluadores y editores que enriquecieron y mejoraron el manuscrito con sus observaciones. Las tareas de campo fueron financiadas por la Municipalidad de Esperanza, la Fundación Arqueológica del Litoral y el Consejo Nacional de Investigaciones Científicas y Técnicas. 


\section{Referencias citadas}

» Andrews, A. P. (1990). Owls, caves and fossils. Chicago: University of Chicago Press.

» Arturi, M. (2005). Situación ambiental en la Ecorregión Espinal. En A. D. Brown y J. Corcuera (Eds.), Situación Ambiental Argentina (pp. 240-246). Buenos Aires: Editorial Fundación Vida Silvestre.

» Balducci, F. (2021). Análisis Arqueológico Integral de la Tecnología Cerámica de Cuencas Fluviales del Centro-Este Santafesino (ríos Coronda y Salado del Norte). (Tesis doctoral en elaboración), Universidad Nacional de Córdoba, Argentina.

» Balducci, F., Sartori, J. I., Frère, M. M. y Gónzalez, M. I. (2019). Improntas textiles en la alfarería del centro-este santafesino: el sitio arqueológico Arroyo Cululú 1 (Esperanza, Santa Fe). En Libro de Resúmenes del VIII Encuentro de Discusión Arqueológica del Nordeste (pp. 26-27). Posadas.

» Balfet, H., Fauvet Berthelot, M. F. y Monzón S. (1992). Normas para la Descripción de Vasijas Cerámicas. México: Centre D'Études Mexicaines et Centraméricaines.

» Banning, E. B. (2000). Archaeologist's Laboratory: the Analysis of Archaeological Data. Nueva York: Springer Science \& Business Media.

» Barrientos, G., Oliva, F. y del Papa, M. (2002). Historia pre y postdepositacional del entierro secundario del sitio Laguna Los Chilenos 1 (provincia de Buenos Aires). Relaciones de la Sociedad Argentina de Antropología, XXVII, 303-325.

» Barrientos, G., Goñi, R., Zangrando, A., del Papa, M., García Guraieb, S., Arregui, M. y Negro, C. (2007). Human taphonomy in Southern Patagonia: a view from the Salitroso lake basin (Santa Cruz, Argentina). En M. Gutiérrez, L. Miotti, G. Barrientos, G. Mengoni Goñalons y M. Salemme (Eds.), Taphonomy and Zooarchaeology in Argentina (pp. 187-201). Oxford: BAR International Series 1601.

» Behrensmeyer, A. (1978). Taphonomic and ecologic information from bone weathering. Palaeobiology, 4(2), 150-162.

» Bonomo, M., Politis, G., Silva, C., Bastourre, L., Ramos van Raap, M. A., Castiñeira Latorre, C., Scabuzzo, C. y Apolinaire, E. (2015). Estado actual de las investigaciones en la localidad arqueológica Laguna de los Gansos (Diamante, Entre Ríos). Revista del Museo de Antropología, 9(2), 51-66. https://doi.org/10.31048/1852.4826.v9.n2.14530

» Buikstra, J. E. y Ubelaker, D. H. (1994). Standards for Data Collection from Human Skeletal Remains. Arkansas: Arkansas Archaeological Survey Research Series № 44.

» Burkart, R., Bárbaro, N., Sánchez, R. y Gómez, D. (1999). Ecorregiones de la Argentina. Buenos Aires: Administración de Parques Nacionales.

»Castellanos, A. (1924). Contribución al estudio de la paleoantropología argentina. Restos descubiertos en el arroyo Cululú (Pcia. de Santa Fe). Revista de la Universidad Nacional de Córdoba, 11(7-9), 48.

»Ceruti, C. (1986). Algo sobre crítica y autocrítica en Arqueología. Revista de Antropología, 1(1), 19-24.

»Ceruti, C. (1987). Investigaciones arqueológicas en la cuenca del Paraná medio: subcuenca del Salado y Saladillos. Informe al CONICET. Manuscrito inédito.

»Ceruti, C. (1988). Modificación ambiental y adaptación cultural en la cuenca del Paraná medio. Trabajo presentado en IX Congreso Nacional de Arqueología Argentina, Buenos Aires, Argentina.

» Ceruti, C. (1995). Libreta de campaña. Manuscrito inédito.

»Ceruti, C. (2000). Ríos y praderas los pueblos del Litoral. En M. Tarragó (Ed.), Nueva Historia Argentina. Los Pueblos Originarios y la Conquista, Tomo I (pp. 105-146). Buenos Aires: Sudamericana. 
»Ceruti, C. (2006). Movimientos poblacionales en el Chaco santafesino. Una visión desde la Arqueología. Folia Histórica del Nordeste, 16, 21-38.

» Cocco, G. (2004). Investigaciones arqueológicas en el Bajo de los Saladillos y sistema lagunar Capón-Setúbal-Leyes. En C. Gradín y F. Oliva (Eds.), El área Pampeana-su pasado (pp. 25-35). Rosario: Laborde.

» Convención Nacional de Antropología (1966). Primera Convención Nacional de Antropología. Córdoba: Universidad Nacional de Córdoba.

» Cornaglia Fernández, J. (2012). Análisis taxonómico e inferencias paleoambientales en el sudoeste santafesino. El sitio arqueológico Laguna El Doce. Revista del Museo de La Plata, 13, 1-16.

» Cornero, S. (1999). Enterratorios humanos en el Litoral: Sitio La Lechuza, Alejandra, depto. San Javier, Santa Fe. En Actas XII Congreso Nacional de Arqueología Argentina III (pp. 384388). La Plata.

» Cremonte, M. B. y Bugliani, M. F. (2006-2009). Pastas, formas e iconografía. Estrategias para el estudio de la cerámica arqueológica. Xama, 19-23, 239-262.

» Daniels, V. (1981). Manganese-containing stains on excavated pottery sherds. Masca Journal, 1, 230-231.

» Di Prado, V. y Castro, J. C. (2014). Estrategia de remontajes aplicada sobre el registro cerámico del sitio Los Tres Cerros 1 (Delta Superior del río Paraná). Revista del Museo de Antropología, $7(2), 263-270$.

» Feuillet Terzaghi, M. R. (2009). El registro Bioarqueológico de la Cuenca Inferior del Río Salado y Cuenca del Río Coronda (Margen Derecha, Provincia de Santa Fe). (Tesis Doctoral inédita), Universidad Nacional de Rosario, Argentina.

» Fernández Ibáñez, C. (2003). Las sales y su incidencia en la conservación de la cerámica arqueológica. En C. Fernández Ibáñez y R. Palacio (Eds.), La Conservación del Material Arqueológico Subacuático (pp. 304-325). Cantabria: Ayuntamiento de Santoña.

»Frenguelli, J. (1920). Excursión a los alrededores de Esperanza. Boletín de la Academia Nacional de Ciencias de Córdoba, 24, 257-292.

» Galligani, P. E. (2020). Preservación Ósea Diferencial en un Ambiente Subtropical del CentroEste de Argentina: Tafonomía Regional en Perspectiva Arqueológica. Oxford: Bar International Series 3003. https://doi.org/10.30861/9781407357300

» Galligani, P. E., Sartori, J. I., Balducci, F. y Barrientos G. (2017). Nuevos hallazgos en la cuenca del río Salado del Norte: el sitio arqueológico Arroyo Cululú 1 (Esperanza, departamento Las Colonias, Santa Fe, Argentina). Anuario de Arqueología, 9, 5-24.

» Galligani, P., Sartori J. y Barrientos, G. (2019). Bacterial bioerosion in human and animal bones from subtropical environments (Northern Pampa/Middle Paraná River Basin, República Argentina). Journal of Archaeological Science: Reports, 25, 561-574. DOI: https://doi. org/10.1016/j.jasrep.2019.05.015

» García Roselló, J. y Calvo Trías, M. (2006). Análisis de las evidencias macroscópicas de cocción en la cerámica prehistórica: una propuesta para su estudio. Mayurqa, 31, 83-112.

» Gascue, A., Bortolotto, N., Loponte, D., Acosta, A., Borges, C., Fleitas, M. y Fodrini, A. (2019). Contextos geomorfológicos y tecnoeconómicos del registro arqueológico del bajo río Uruguay (margen izquierda). Resultados preliminares de nuevas prospecciones. Arqueología, 25(3), 87-117. https://doi.org/10.34096/arqueologia.t25.n3.7325

» Goldstein, L. (1989). The ritual of secondary disposal of the dead. Trabajo presentado en 1989 Theoretical Archaeological Group meetings, Newcastle, Reino Unido.

» Goldstein, L. (1995). Landscapes and Mortuary Practices. A case for Regional Perspectives. En: A. Beck (Ed.), Regional Approaches to Mortuary Practices (pp. 101-121). Nueva York: Plenum Press.

» González, M. I. y Frère, M. M. (2010). Diseños Prehispánicos de la Alfarería Pampeana. Buenos Aires: Editorial de la Facultad de Filosofía y Letras. 
» Gutiérrez, M. (2004). Análisis Tafonómicos en el Área Interserrana (Provincia de Buenos Aires). (Tesis Doctoral inédita), Universidad Nacional de La Plata, Argentina.

» Gutiérrez, M. y Kaufmann, C. (2007). Methodological criteria for the identification of formation processes in guanaco (Lama guanicoe). Bone assemblages in fluvial-lacustrine environments. Journal of Taphonomy, 5, 151-176.

» Krenzer, U. (2006). Compendio de Métodos Antropológico Forenses Para la Reconstrucción del Perfil Osteo-biológico. Guatemala: DED.

» Kröhling, D. y Brunetto, E. (2013). Marco geológico y geomorfológico de la cuenca del Arroyo Cululú. En O. Giayetto, J. Plevich, V. H. Lallana y M. Pilatti (Comps.), Bases Conceptuales y Metodológicas Para el Ordenamiento Territorial del Medio Rural (pp. 485-511). Río Cuarto: Libroclic ediciones.

» Lovejoy, C. (1985). Dental wear in the Libben population. Its functional pattern and role in the determination of adult skeletal age at death. American Journal of Physical Anthropology, 68, 47-56. https://doi.org/10.1002/ajpa.1330680105

» Lyman, R. L. (1994). Vertebrate taphonomy. Cambridge: University Press.

» Lyman, R. L. (2008). Quantitative Paleozoology. Cambridge: University Press.

» Mazza, B y Béguelin, M. (2013). Determinación sexual de los entierros secundarios del sitio arqueológico Cerro Lutz mediante funciones discriminantes de huesos largos. Cuadernos del Instituto Nacional de Antropología y Pensamiento Latinoamericano - Series Especiales, 1(1), 121-134.

» Mazza, B. y Loponte, D. (2012). Las prácticas mortuorias en el humedal del Paraná inferior. Arqueología Iberoamericana, 13, 3-21.

» Mengoni Goñalons, G. (1999). Cazadores de guanaco de la estepa patagónica. Buenos Aires: Sociedad Argentina de Antropología. Colección de Tesis Doctorales.

» Mengoni Goñalons, G. (2006-2010). Zooarqueología en la práctica: algunos temas metodológicos. Xama, 19-23, 83-113.

» Mondini, M. (2003). Modificaciones óseas por carnívoros en la Puna argentina. Una mirada desde el presente a la formación del registro arqueofaunístico. Mundo de Antes, 3, 87-108.

» Oakley, L., Prado, D. y Ádamoli, J. (2005). Aspectos Biogeográficos del Corredor Fluvial Paraguay-Paraná. Miscelánea, 14, 245-258.

»Ottalagano, F. (2016). Investigaciones arqueológicas en el sitio Arroyo Arenal I: cuenca media del río Paraná (Entre Ríos, Argentina). Cuadernos del Instituto Nacional de Antropología y Pensamiento Latinoamericano, 25(2), 159-176.

»Paoli, C. (2004). Inundaciones ribereñas en el tramo del Paraná Medio. En J. C. Bertoni (Ed.), Inundaciones Urbanas en Argentina (pp. 75-114). Córdoba: Universidad Nacional de Córdoba.

» Paoli, C., Hämmerly, R., Giacosa, R., Sosa, D., Cacik, P. y Villordo A. (2013). Los cambios globales en el régimen hidrológico de la cuenca del Arroyo Cululú. En O. Giayetto, J. Plevich, V. H. Lallana y M. Pilatti (Comps.), Bases Conceptuales y Metodológicas Para el Ordenamiento Territorial del Medio Rural (pp. 449-472). Río Cuarto: Libroclic ediciones.

» Pautasso, A., Peña, M., Mastropaolo, J. y Moggia, L. (2002). Distribución y conservación del venado de las pampas (Ozotoceros bezoarticus leucogaster) en el norte de Santa Fe, Argentina. Mastozoología Neotropical, 9(1), 64-69.

» Pérez, M. (2016). Tecnología de producción y uso de la alfarería durante el holoceno tardío en el humedal del Paraná inferior. (Tesis doctoral inédita), Universidad Nacional de Buenos Aires, Argentina.

»Pilatti, M. A. (2013). Aguas superficiales; cursos naturales y canales. En O. Giayetto, J. Plevich, V. H. Lallana y M. Pilatti (Comps.), Bases Conceptuales y Metodológicas Para el Ordenamiento Territorial del Medio Rural (pp. 437-443). Río Cuarto: Libroclic ediciones.

» Rye, O. (1981). Pottery Technology: Principles and Reconstruction. Washington, DC: Taraxacum. 
» Sanhueza Riquelme, L. (1998). Antecedentes y proposición metodológica para el estudio de huellas de alteración en la cerámica. Conserva, 2, 69-79.

» Sartori, J. I., Galligani, P. E. y Balducci, F. (2019). Análisis zooarqueológico en dos sitios del Espinal santafesino (Esperanza, provincia de Santa Fe). Trabajo presentado en el $5^{\circ}$ Congreso Nacional de Zooarqueología Argentina, San Fernando del Valle de Catamarca, Argentina.

» Sartori, J., Colasurdo M. B. y Santiago, F. (2014). Zooarchaeology in the Paraná River flood plain: GIS implementation at a regional scale. Journal of Anthropology and Archaeology, 2(2), 77-106. 10.15640/jaa.v2n2a4

» Sartori, J., Santiago, F. y Colasurdo, M. B. (2017). El espacio y los recursos: el análisis arqueofaunístico mediante SIG en los distintos ambientes de la provincia de Santa Fe (Argentina). Antípoda. Revista de Antropología y Arqueología, 28, 99-125.

» Scabuzzo, C., Ramos van Raap, M. A., Bonomo, M. y Politis, G. (2015). Estudios bioarqueológicos en el sitio Los Tres Cerros 1 (Delta Superior del río Paraná, Entre Ríos, Argentina). Boletim do Museu Paraense Emílio Goeldi. Ciências Humanas, 10(2), 509-535. http://dx.doi.org/10.1590/1981-81222015000200015.

» Schaefer, M., Black, S. y Scheuer, L. (2009). Juvenile Osteology. A Laboratory and Field Manual. Burlington: Academic Press.

» Schiffer, M. y Skibo, J. (1989). A provisional theory of ceramic abration. American Anthropologist, 91(1), 101-115.

» Schutkowski, H. (1993). Sex determination of infant and juvenil skeletons: I. Morphognostic features. American Journal of Physical Anthropology, 90, 199-205. https://doi.org/10.1002/ ajpa.1330900206

»Skibo, J. (1987). Fluvial sherd abrasion and the interpretation of surface remains on Southwestern bajadas. North American Archaeologist, 8, 125-142. 10.2190/0J02-23DB-34HV2PFV

» Skibo, J. (1992). Pottery Function: a Use-Alteration Perspective. Nueva York: Plenum Press.

» Sprague, R. (2005). Burial Terminology: A Guide for Researchers. Oxford: Altamira Press.

»Ubelaker, D. (1999). Human Skeletal Remains: Excavation, Analysis, Interpretation. Washington, DC: Taraxacum.

»Vignati, M. (1923). Nótula sobre el hombre fósil del Arroyo Cululú, provincia de Santa Fe. Physis, 7, 62-65.

» Vignati, M. (1931). Un vestigio de la queratotecnia del hombre fósil de Esperanza. Notas preliminares del Museo de La Plata, 1, 7-17.

» Vignati, M. (1934). El hombre fósil de Esperanza. Notas preliminares del Museo de La Plata, 3, 7-75. 